\title{
Effect of resveratrol in type 2 diabetes oxidative stress markers: a reassessment
}

\author{
Venu Gopal Jonnalagadda ${ }^{1}$ Harish Prabhanna Char $^{2}$
}

Received: 24 January 2018 / Accepted: 2 May 2018 / Published online: 23 May 2018

c) Springer-Verlag Italia S.r.l., part of Springer Nature 2018

\section{Dear Editor,}

We have read the research article "The effects of resveratrol on markers of oxidative stress in patients with type 2 diabetes: a randomized, double-blind, placebo-controlled clinical trial" by Seyyedebrahimi et al., the authors presented comparative study results of resveratrol on oxidative stress parameters in type 2 diabetes mellitus (T2DM) participants [1]. We would like to request the authors to clarify or elucidate the following points for further understanding.

First, the authors mentioned that participants were randomized using a stratification method in a double-blind manner and did not mention about the criteria for the same [1]. However, stratification method can be performed based on different factors, i.e., gender, age or other demographic characteristics and leads to bias in grouping [2].

Second, the authors mentioned that patients were refrained from the anti-inflammatory supplementation during the entire study. However, the patients were on statins in

Managed by Massimo Porta.

This comment refers to the article available at https://doi. org/10.1007/s00592-017-1098-3.

Reply to this comment refers to the article available at https://doi. org/10.1007/s00592-018-1154-7.

Venu Gopal Jonnalagadda

gopalvenu63@gmail.com

Harish Prabhanna Char

pharish9@gmail.com

1 Department of Pharmacology and Toxicology, National Institute of Pharmaceutical Education and Research, C/O NETES Institute of Technology and Science, NH-37, Shantipur, Parli Part, Mirza, Assam 781125, India

2 National Institute of Management Studies, 201 Nirman Estate, Link Road, Malad West, Mumbai, Maharashtra 400064, India both the groups, i.e., $75 \%$ in placebo and $70 \%$ in resveratrol and these itself have an anti-inflammatory effect [3].

Third, in Fig. 1, the number of participants in the placebo group was presented as 25 , but, in Table 1 it is mentioned as 18 .

Fourth, a dose of resveratrol was considered as $800 \mathrm{mg} /$ day, but, did not mention the reference for this dose as $800 \mathrm{mg} /$ day seems to be high.

Fifth, the baseline HOMA-IR value of placebo mentioned as $5.75 \pm 5.74$, which means the mean and the standard deviation in this group are same, i.e., 11.49 or 0.01 . Thus, there is a large variation in this group.

We would be highly obliged for your kind consideration of the above-mentioned clarifications in your article to understand more beneficial effects of bioactive compound i.e., resveratrol on oxidative parameters in T2DM.

Funding This paper was not funded.

\section{Compliance with ethical standards}

Conflict of interest The authors declare that they have no competing interests. The authors have no relevant affiliations or financial involvement with any organization or entity.

\section{References}

1. Seyyedebrahimi S, Khodabandehloo H, Nasli Esfahani E, Meshkani R (2018) The effects of resveratrol on markers of oxidative stress in patients with type 2 diabetes: a randomized, doubleblind, placebo-controlled clinical trial. Acta Diabetol. https://doi. org/10.1007/s00592-017-1098-3

2. Polit DF, Beck CT (2008) Nursing research: generating and assessing evidence for nursing practice, 9 th edn. Wolters Klower Health, Lippincott Williams \& Wilkins, Philadelphia

3. Lefer DJ (2002) Statins as potent antiinflammatory drugs. Circulation 106:2041-2042 